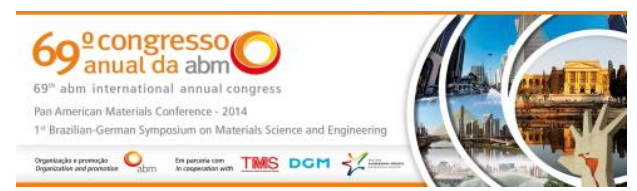

Tema: Metalurgia do Pó

\title{
CARACTERIZAÇÃO DE LIGAS Fe-Ni PROCESSADAS POR METALURGIA DO PÓ: INFLUÊNCIA DOS PARÂMETROS NAS PROPRIEDADES MECÂNICAS*
}

\section{Resumo}

Giovani Gonçalves Ribamar ${ }^{1}$ Candido Jorge de Solsa Lobo² Marcelo José Gomes da Silva ${ }^{3}$

A metalurgia do pó torna-se um processo importante para obtenção de peças com geometria complexa, tornando-as cada vez mais viáveis. O objetivo desse trabalho é caracterizar e avaliar a influência da energia de mistura e tempo de mistura na microestrutura e propriedades mecânicas (dureza) da liga $\mathrm{Fe} 70 \%$ - $\mathrm{Ni} 30 \%$, utilizadas em componentes eletrônicos e materiais estruturais de peças de motores automotivos, sendo produzidas por metalurgia do pó (MP). As ligas Fe-Ni foram misturadas a baixa e alta energia, $25 \mathrm{rpm}$ e $200 \mathrm{rpm}$, respectivamente, por 2 (duas) e 4 (quatro) horas, compactadas uniaxialmente a frio com pressão de compactação de 8 toneladas e sinterizadas a $1.100^{\circ} \mathrm{C}$. Foram realizadas simulações para previsão das fases presentes através do software de simulação termodinâmica, Thermo-Calc, onde mostrou a possível existência de fases CCC e CFC. A microestrutura foi avaliada por Microscopia Eletrônica de Varredura (MEV), possibilitando a visualização da quantidade e do tamanho dos poros, bem como forma e tamanho dos grãos. Foi realizada espectroscopia de energia dispersiva (EDS) para análise química pontual e mapeamento químico

Palavras-chave: Ligas Fe-Ni; Metalurgia do pó; Caracterização.

\section{CHARACTERIZATION OF Ni-Fe ALLOYS PROCESSED BY POWDER METALLURGY: INFLUENCE OF PARAMETERS ON MECHANICAL PROPERTIES}

\section{Abstract}

Powder metallurgy becomes an important process for obtaining pieces with complex geometry, making them increasingly viable. The aim of this work is to characterize and evaluate the influence of mixing energy and mixing time on the microstructure and mechanical properties (hardness) of the alloy $\mathrm{Fe} 70 \%-30 \% \mathrm{Ni}$, used in electronics and structural materials of automotive engine parts, being produced by powder metallurgy (PM). The Fe-Ni alloys were mixed at low and high energy, 25 and $200 \mathrm{rpm}$, respectively, for 2 and 4 hours, uniaxially cold compacted with compaction pressure of 8 tons and sintered at $1,100^{\circ} \mathrm{C}$. Simulations to predict the phases present were performed using thermodynamic simulation by the software Thermo-Calc, which showed the possible existence of CCC and CFC phases. The microstructure was evaluated by Scanning Electron Microscopy (SEM), enabling visualization of the amount and size of pores, as well as shape and size of the grains. Energy dispersive spectroscopy (EDS) for chemical mapping punctual and chemical analyzes was used.

Keywords: Fe-Ni alloys; Powder metallurgy; Characterization.

1 Engenharia Metalúrgica, graduando, Departamento de Engenharia Metalúrgica e de Materiais, Universidade Federal do Ceará, Fortaleza, CE, Brasil.

2 Engenharia e Ciência dos Materiais, mestre, professor, Departamento de Ciências Ambientais e Tecnológicas, Universidade Federal Rural do Semi-Árido, Mossoró, RN, Brasil.

3 Engenharia Nuclear, Doutor, professor, Departamento de Engenharia Metalúrgica e de Materiais, Universidade Federal do Ceará, Caucaia, CE, Brasil.

\footnotetext{
* Contribuição técnica ao 69 Congresso Anual da ABM - Internacional e ao 14ํㅡㄹ ENEMET - Encontro Nacional de Estudantes de Engenharia Metalúrgica, de Materiais e de Minas, 21 a 25 de julho de 2014, São Paulo, SP, Brasil.
} 


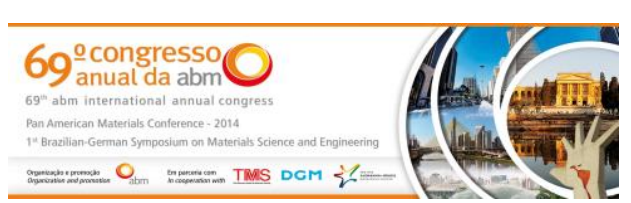

\section{INTRODUÇÃO}

Sendo um dos processos de fabricação mais antigos que se tem conhecimento, a metalurgia do pó (MP) vem proporcionando inúmeras possibilidades de produção de ligas, até então, quase impossível pela metalurgia convencional. Hoje são inúmeras as aplicações industriais de peças produzidas por este processo. Comparada a metalurgia convencional, esta tecnologia torna-se competitiva tanto por razões econômicas como por razões tecnológicas, sendo utilizada, por exemplo, para a fabricação de grande quantidade de peças, de formas complexas ou com material base de alto ponto de fusão.

Schaerer [5] define MP como o ramo da indústria metalúrgica direcionado à produção de peças a partir de pós metálicos ou não metálicos, através de etapas importantes como obtenção do pó, compactação e tratamento de sinterização, quando necessário, em temperaturas abaixo do ponto de fusão do material de base, resultando em produtos com dimensões altamente precisas e com propriedades mecânicas desejadas.

\subsection{Pós Metálicos}

Os vários métodos de produção dos pós-metálicos, sejam eles: eletrolítico, redução, atomização de metais líquidos, mecânicos, etc., conduzem ao pó metálico diversas formas, tamanhos e distribuição granulométrica, características de grande importância para as propriedades finais da liga. Quanto mais irregular for a partícula, maior será a área superficial específica livre para interação entre as moléculas na sinterização, formando uma peça mais compacta e com melhores propriedades mecânicas. Quanto ao tamanho das partículas, uma partícula maior permite maior compactação, enquanto uma menor permite uma superfície com menor rugosidade.

\subsection{Compactação}

A consolidação do pó consiste uma importante etapa na fabricação de produtos na metalurgia do pó, parte dessa transformação consiste na compactação de uma massa para a produção do compactado verde, que poderá ser submetido ao processo de sinterização para obtenção de uma estrutura mais coerente, se necessário.

\subsection{Sinterização}

A força motora para a ocorrência de qualquer tipo de sinterização é a diminuição da energia livre superficial do conjunto de partículas. Entre os dois tipos básicos de sinterização estão:

\subsubsection{Sinterização por fase sólida}

Geralmente utilizada quando se deseja controle na porosidade. O material é transportado sem que haja qualquer tipo de líquido na estrutura, seja por fluxo viscoso, difusão atômica ou por transporte de vapor.

\subsubsection{Sinterização por fase líquida}

Acontece devido à formação de líquido na estrutura, podendo este ser causado pela fusão de um dos componentes do sistema ou do resultado de uma reação entre pelo

\footnotetext{
* Contribuição técnica ao 69 Congresso Anual da ABM - Internacional e ao 14ํㅡㄹ ENEMET - Encontro Nacional de Estudantes de Engenharia Metalúrgica, de Materiais e de Minas, 21 a 25 de julho de 2014, São Paulo, SP, Brasil.
} 


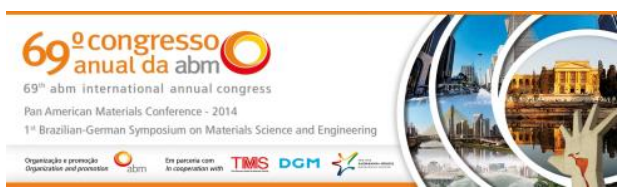

menos dois dos componentes do sistema. Esta forma de sinterização torna-se atraente quanto a consolidação de materiais dificilmente sinterizáveis por fase sólida e para a obtenção de materiais compósitos.

\subsection{Moagem de Alta Energia}

O processo de Moagem de Alta Energia (MAE) consiste em uma síntese mecanoquímica em que as misturas de pós de diferentes metais ou ligas são moídas conjuntamente para a obtenção de uma liga homogênea, através da transferência de massa. Durante o processo, as partículas de pó são continuamente deformadas, soldadas a frio, quebradas e resoldadas. A técnica consiste basicamente no processamento de materiais na forma de pós, juntamente com corpos de moagem, que podem ser esferas de aço ou outro material de alta dureza, inseridos em um vaso de moagem, geralmente feito do mesmo material das esferas. Por vibração ou rotação as esferas chocam-se com as paredes do vaso resultando em uma prensagem do pó a cada impacto e deste modo o pó é repetidamente levado a solda, fratura e ressolda num intenso processo cíclico de transferência de energia que possibilita a nanoestruturação dos materiais moídos.

Durante a moagem de alta energia, alta deformação é introduzida nas partículas. Isso é manifestado pela presença de vários defeitos cristalinos, tais como discordâncias, vazios, falhas de empilhamento e aumento no número de contornos de grão. A presença desses defeitos, além do refinamento da microestrutura, diminui as distâncias de difusão e do aumento da temperatura durante a moagem e aumentam a difusividade dos elementos solutos na matriz, resultando na produção de pós com alta sinterabilidade em relação à moagem convencional.

Velocidade de moagem, temperatura, tempo de moagem, tipo de moinho, relação mássica bola/pó, atmosfera de moagem e material do cadinho estão entre os parâmetros influentes nas características finais do pó após a moagem.

Com o aumento da velocidade de rotação do moinho, maior a energia transferida ao pó, porém existirão certas limitações para a velocidade máxima a ser empregada na moagem. Com o aumento da velocidade de moagem o movimento das esferas pode não ocorrer e também, a temperatura no interior do recipiente pode alcançar valores muito elevados, chegando a alguns casos a promover energia necessária para transformações de fases.

O tempo de moagem é ponderado uma das mais importantes variáveis na moagem de alta energia, sendo que este irá ditar o ponto de equilíbrio entre fratura e soldagem a frio do pó. Por questões produtivas, é preferível curtos períodos de moagem, além de que, tempos longos contribuem para o aumento da temperatura, influenciando diretamente na contaminação, aparecimento de fases indesejadas e heterogeneização química e microestrutural.

\subsection{Ligas Ferro Níquel}

O Níquel é estabilizador da austenita (CFC), e esta fase possui propriedade mecânica mais elevada que a fase ferrítica. No plano da metalurgia do pó, o níquel forma solução sólida substitucional com o ferro. Essas ligas são caracterizadas por terem boas propriedades mecânicas e de resistência à corrosão, tendo uma vasta aplicação em componentes mecânicos.

\footnotetext{
* Contribuição técnica ao $69^{\circ}$ Congresso Anual da ABM - Internacional e ao 14ํㅡㄹ ENEMET - Encontro Nacional de Estudantes de Engenharia Metalúrgica, de Materiais e de Minas, 21 a 25 de julho de 2014, São Paulo, SP, Brasil.
} 


\section{MATERIAIS E MÉTODOS}

\subsection{Materiais de Consumo}

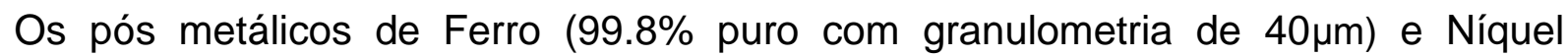
(99.2\% puro com granulometria de $55 \mu \mathrm{m})$ foram fornecidos pela indústria IMASH (SP).

\subsection{Equipamentos Utilizados}

Os equipamentos utilizados são citados nas seções subsequentes de acordo com as diferentes etapas do trabalho.

\subsubsection{Fabricação dos corpos de prova}

Para a moagem dos pós-metálicos, foi utilizado um moinho de bolas com cadinho para os pós, de aço inoxidável e esferas de aço. A relação mássica esferas/pó utilizada foi de 10:1. De acordo com a velocidade do moinho e do tempo de moagem, os corpos de prova foram identificados de acordo com a Tabela 1 a seguir.

Tabela 1. Identificação dos corpos de prova

\begin{tabular}{ccc}
\hline & $25 \mathrm{rpm}$ & $200 \mathrm{rpm}$ \\
\hline 12 horas & $\mathrm{A} 1$ & \\
\hline 1 hora de mistura & $\mathrm{B} 1$ \\
\hline 4 horas de mistura & $\mathrm{C} 1$ \\
\hline
\end{tabular}

Logo após a moagem dos corpos de prova, os mesmos foram levados à compactação, utilizando-se o equipamento eletromecânico para ensaio de tração Instron Modelo 4484 e um molde cilíndrico de $15 \mathrm{~mm}$ de diâmetro na cavidade de compactação. A pressão aplicada para a compactação foi a equivalente a de 2 toneladas.

A seguir foi realizada a sinterização dos corpos de prova a $1100^{\circ} \mathrm{C}$ durante 1 hora em um forno tipo mufla, sem proteção gasosa, seguido de resfriamento ao forno. Para a liga $\mathrm{C} 1$ o resfriamento foi nitrogênio para rápido resfriamento da liga, impedindo ao máximo a difusão dos elementos na liga (têmpera ao nitrogênio).

\subsubsection{Preparação e caracterização microestrutural dos corpos de prova}

Foram utilizadas lixadeira rotativa com lixas de granulometria de 220, 320, 400, 600 e 1200. A seguir prosseguiu-se a preparação da superfície com polimento com pastas de diamante de granulometria 6,3 e $1 \mu$.

Terminado a preparação e limpeza da superfície, utilizou-se do reagente Nital $4 \%$ (4 mL de ácido nítrico + $96 \mathrm{~mL}$ de álcool) para revelação da microestrutura das ligas. Analisou-se a microestrutura através de um Microscópio Eletrônico de Varredura Philips XL30 com EDS. Foram realizadas medidas de composição química através de espectroscopia de energia dispersiva (EDS).

As medidas de microdureza foram realizadas em um microdurômetro de dureza Vickers Shimadzu com carga HV 1 por 15 segundos. As medidas de dureza foram realizadas em durômetro Rockwell, utilizando escala de dureza B.

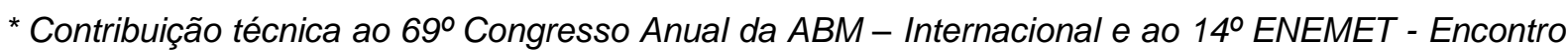
Nacional de Estudantes de Engenharia Metalúrgica, de Materiais e de Minas, 21 a 25 de julho de 2014, São Paulo, SP, Brasil.
} 


\section{RESULTADOS E DISCUSSÃO}

A amostra A1 foi misturada por 12 horas para garantir a total mistura da liga. Após a mistura, as ligas foram compactadas a pressão de 2 toneladas, porém, para as ligas misturadas a alta energia, $200 \mathrm{rpm}$, o compactado não apresentava firmeza suficiente para seu transporte até o forno de sinterização, sendo necessário a compactação a pressão mais elevada, 8 toneladas.

Após a sinterização a $1100^{\circ} \mathrm{C}$ para todas as ligas, foi realizada preparação metalográfica com: embutimento, lixamento, polimento e em alguns casos ataque químico para posterior análise em Microscópio Eletrônico de Varredura, como mostrado nas Figuras a seguir.

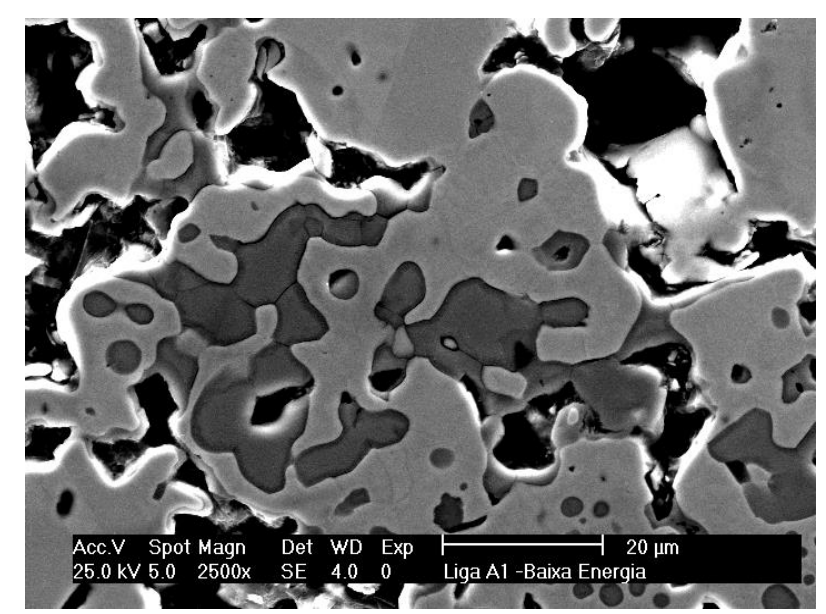

Figura 1. Micrografia eletrônica de Varredura da liga A1. Aumento 2.500x. Sem ataque.

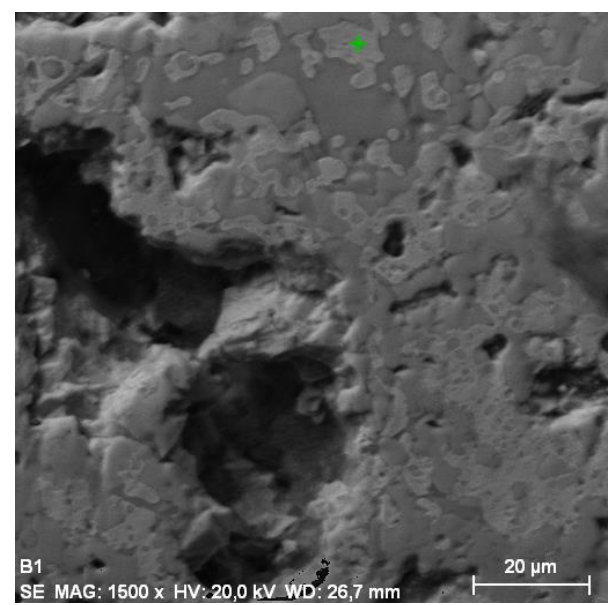

Figura 2. Micrografia eletrônica de Varredura da liga B1. Aumento 1.500x. Sem ataque.

\footnotetext{
* Contribuição técnica ao $69^{\circ}$ Congresso Anual da ABM - Internacional e ao 14ํㅡㄹ ENEMET - Encontro Nacional de Estudantes de Engenharia Metalúrgica, de Materiais e de Minas, 21 a 25 de julho de 2014, São Paulo, SP, Brasil.
} 


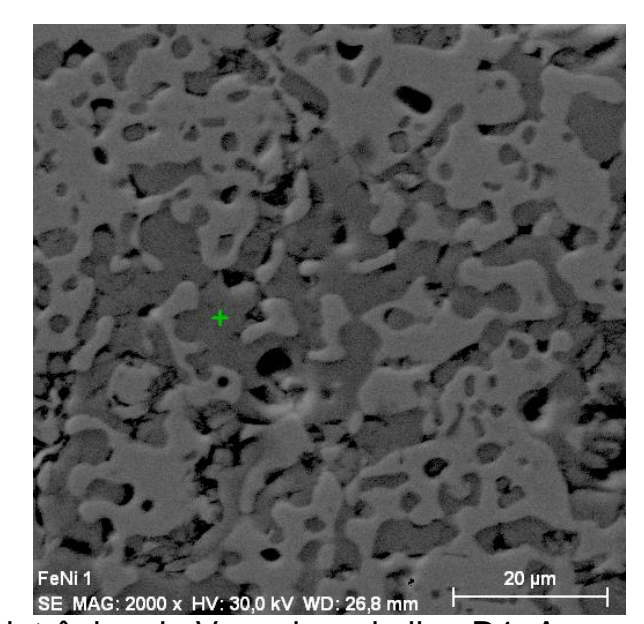

Figura 3. Micrografia eletrônica de Varredura da liga D1. Aumento 2.000x. Sem ataque.

A liga $A 1$ apresentou microestrutura mais homogênea, quase que inteiramente de uma região clara (Fase 1), quanto que as ligas B1 e D1 apresentaram uma percentagem maior de uma região mais escura (Fase 2). Diante disso, foram realizados EDX, obtendo-se as composições das duas fases, como mostrado na Tabela 2.

Tabela 2. Percentual em peso de Níquel nas duas fases presentes nas ligas A1, B1 e D1.

\begin{tabular}{ccc}
\hline & Fase 1 & Fase 2 \\
\hline A1 & 11.67 & 0.43 \\
\hline B1 & 23.15 & 2.22 \\
\hline D1 & 49.39 & 1.28
\end{tabular}

Pela Tabela anterior, percebe-se que à medida em que aumenta-se a energia de mistura, a fase 1 enriquece de Níquel, quanto que a fase 2, pouco varia sua composição.

Foram realizados Perfis de composição química para melhor visualização da variação de composição química nas fases 1 e 2, como mostrado nas Figuras 4 e 5.

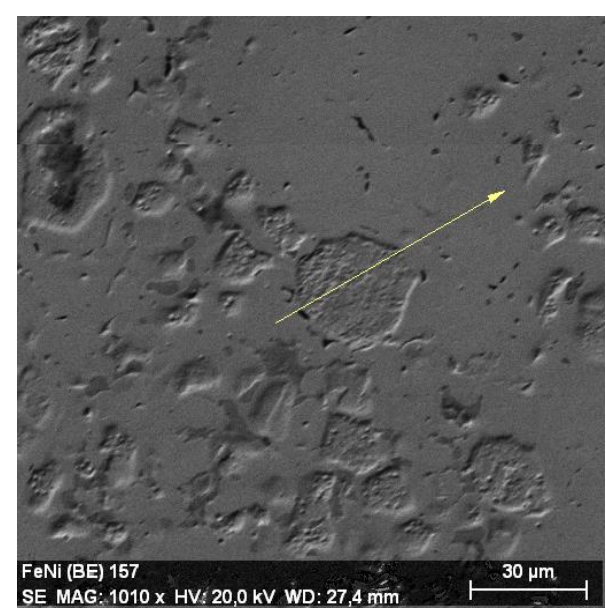

Figura 4. Micrografia eletrônica de Varredura da liga D1 mostrando o perfil de composição química por EDX. Sem ataque.

\footnotetext{
* Contribuição técnica ao $69^{\circ}$ Congresso Anual da ABM - Internacional e ao 14ํㅡㄹ ENEMET - Encontro Nacional de Estudantes de Engenharia Metalúrgica, de Materiais e de Minas, 21 a 25 de julho de 2014, São Paulo, SP, Brasil.
} 

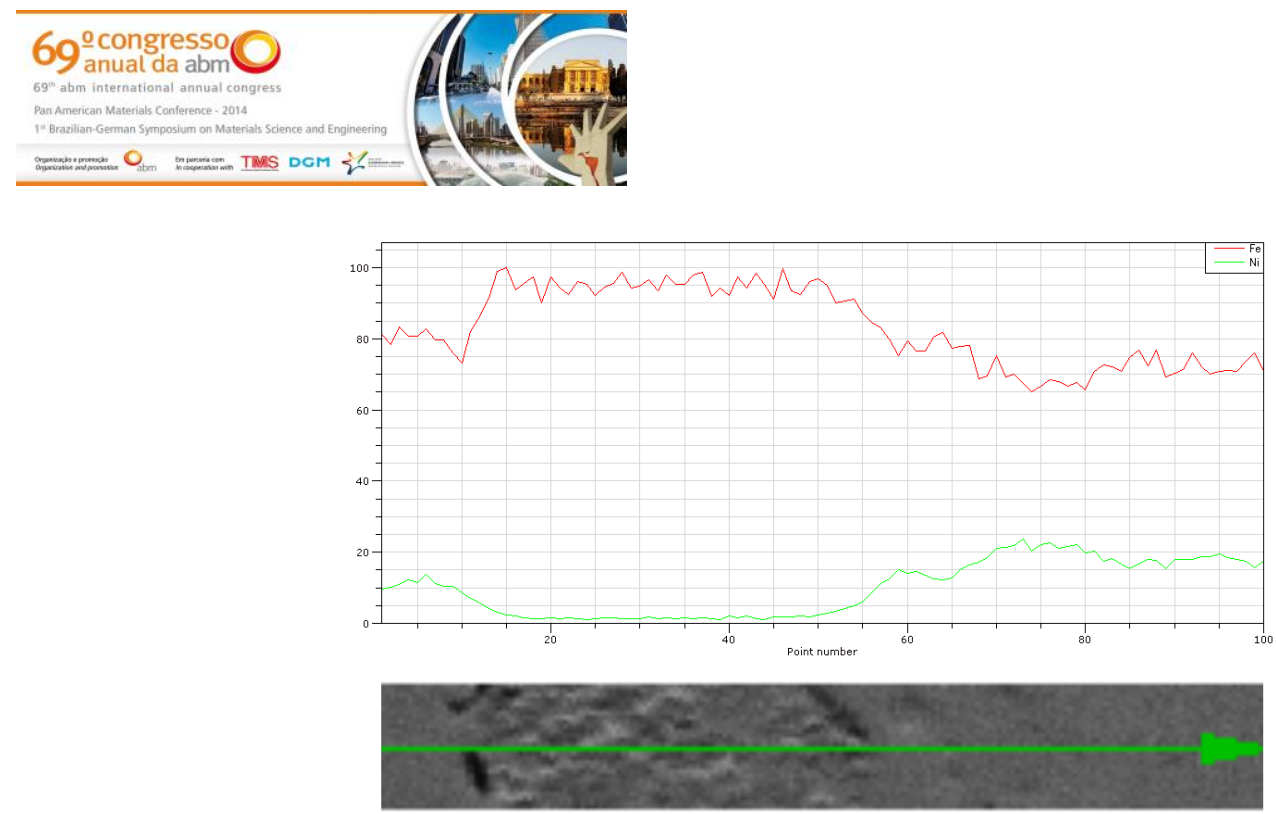

Gráfico 1. Gráfico do Perfil de linha (EDX) realizado na região indicada na Figura 4, referente à liga A1.

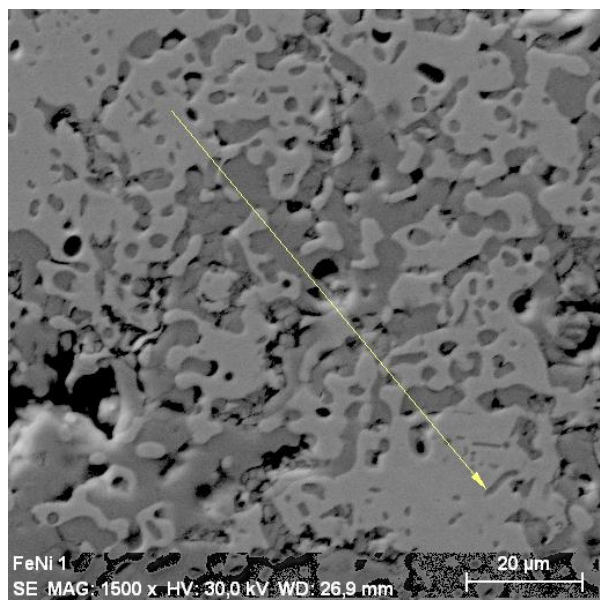

Figura 5. Micrografia eletrônica de Varredura da liga D1 mostrando o perfil de composição química por EDX. Sem ataque.
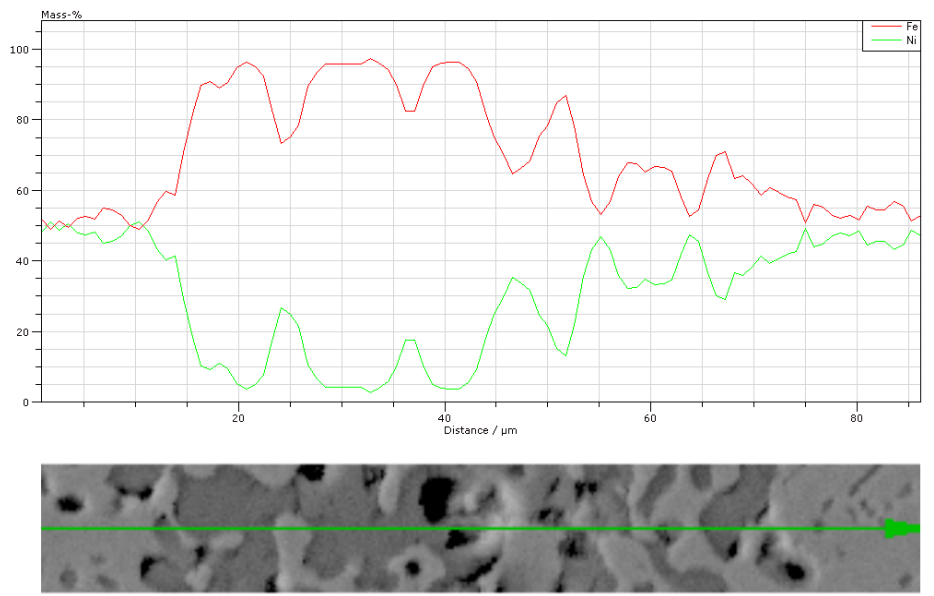

Gráfico 2. Gráfico do Perfil de linha (EDX) realizado na região indicada na Figura 5, referente à liga D1.

Além dessas micrografias, constatou-se que a microestrutura da liga $A 1$, apresentava pequenas partículas dispersas em toda a estrutura, como apresentado na Figura 6.

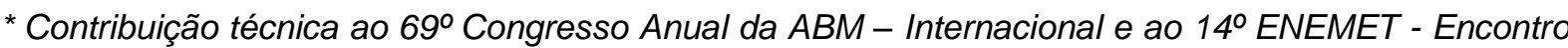
Nacional de Estudantes de Engenharia Metalúrgica, de Materiais e de Minas, 21 a 25 de julho de 2014, São Paulo, SP, Brasil.
} 
Foram realizados ensaio de dureza Rockwell $B$ nas quatro ligas, como mostrado na Tabela 4. Verifica-se que a dureza da liga aumenta com o aumento da energia de moagem, diminuindo quando se chega a um valor crítico de energia.

Tabela 4. Medidas de Dureza Rockwell B e microdureza Vickers HV 1 nas duas fases presentes nas ligas.

\begin{tabular}{cccc}
\hline & Dureza Rockwell B & $\begin{array}{c}\text { Microdureza Vickers - } \\
\text { Fase }\end{array}$ & $\begin{array}{c}\text { Microdureza Vickers - Fase } \\
2\end{array}$ \\
\hline $\mathrm{A} 1$ & 46 & 520 & 120 \\
\hline $\mathrm{B} 1$ & 52 & $\left(^{*}\right)$ & $\left(^{*}\right)$ \\
\hline $\mathrm{C} 1$ & 27 & 102 & 80 \\
\hline $\mathrm{D} 1$ & 45 & 500 & 115 \\
\hline$\left(^{*}\right)$ Não foi possível realizar o ensaio de microdureza desta liga.
\end{tabular}

\section{CONCLUSÃO}

Variando-se a quantidade de energia fornecida para a mistura dos pós metálicos, as duas fases presentes na liga (Fase 1 e Fase 2) apresentam variação em suas composições químicas, aumentando o percentual de níquel consideravelmente na Fase 1 a medida que mais energia é fornecida na mistura. Quanto a Fase 2, nota-se pouca variação em sua composição.

Quanto à medida de dureza, verificamos que, assim como a composição das fases varia com a variação de energia de mistura, a dureza das ligas também, elevando-se de 46 Rockwell B (25 rpm - Liga A1) para 52 (200 rpm por uma hora - Liga B1) e depois diminuindo para 45 Rockwell $B$ com maior tempo de moagem (Liga D1).

Para a liga temperada ao nitrogênio, a liga apresentou maior homogeneização química, estando presente na Fase 1 aproximadamente o mesmo percentual de níquel que na liga D1, quanto que na Fase 2, uma elevação considerável na percentagem de níquel, se comparado as outras ligas.

$\mathrm{A}$ Dureza da liga $\mathrm{C} 1$ apresentou valores muito mais baixos se comparado às outras liga, levando-se a considerar que o motivo para a queda na dureza seja devido a maior distribuição de níquel nas duas fases.

\section{Agradecimentos}

Ao professor e orientador Dr. Marcelo José Gomes da Silva, pelo qual mantenho profundo respeito e admiração.

Ao professor Candido Jorge de Solsa Lobo por além dos ensinamentos, amizade e enorme paciência.

Ao professor Dr. Hamilton Ferreira Gomes de Abreu, pelo também apoio e disposição.

Ao Laboratório de Materiais Cerâmicos, Laboratório de espectroscopia Moss bauer e ao Laboratório Pesquisa em Corrosão (LPC) da Universidade Federal do Ceará, pelo apoio e contribuições referentes à produção das ligas.

A todos os bolsistas e amigos do Laboratório de Caracterização de Materiais (LACAM), em especial a Mirela de Oliveira Castro e ao Antônio Henrique das Virgens Neto pela grande ajuda para a realização deste trabalho.

A Universidade Federal do Ceará (UFC) pelo incentivo científico e financeiro.

\footnotetext{
* Contribuição técnica ao $69^{\circ}$ Congresso Anual da ABM - Internacional e ao 14ํㅡㄹ ENEMET - Encontro Nacional de Estudantes de Engenharia Metalúrgica, de Materiais e de Minas, 21 a 25 de julho de 2014, São Paulo, SP, Brasil.
} 


\section{BIBLIOGRAFIA}

1 ASM Handbook Vol 3 - Binary Alloy Phase Diagrams, ASM International, 1990.

2 Grupo Setorial de Metalurgia do Pó. A Metalurgia do Pó: alternativa econômica com menor impacto ambiental. 1a edição São Paulo: Metallum Eventos Técnicos, 2009. $320 \mathrm{p}$.

3 Tsutsui T. Technical Trends in the development of structural Materials and Outlook for the Future. Disponível em: <www.hitachi-pm.co.jp/tec/tec2008_e_03.pdf>. Acesso em: 22 fev. 2012.

4 Kozelkova I. et al. Kinects of Austenite to Martensite transformations in Iron-NickelCarbone Alloys during their coling or tensile testing. Journal de Physique Iv, Paris, 2005; 5: 323-328.

5 Schaerer MMM. Análise Numérica Do Comportamento De Densificação De Pós Metálicos Resultante Do Processo De Compactação Uniaxial. 2006. 89 f. Tese (Doutor) - Curso de Engenharia Mecânica, Departamento de Coppe, Universidade Federal do Rio de Janeiro, Rio de Janeiro, 2006.

6 Ramakrishnan P. History of Powder Metallurgy. Indian Journal of History Of Sciences, Bombay, 1980; 18(1): 109-114.

7 Santos CN. Aspectos Cristalográficos Da Transformação Martensítica De Uma Liga Fe27\%Ni. 2008. 120 f. Tese (Doutor) - Ime, Rio de Janeiro, 2008. Disponível em: <http://www.ime.eb.br/arquivos/teses/se4/cm/Claudia_Nazare_dos_Santos.pdf>. Acesso em: 12 mar. 2012.

8 Jesus Filho ES. Processamento, Usinagem e Desgate de Ligas Sinterizadas para aplicações automotivas. 2006. 162 f. Tese (Doutor) - Curso de Doutorado em Ciências, Departamento de Tecnologia Nuclear e Materiais, Instituto de Pesquisas Energéticas e Nucleares- IPEN, São Paulo, 2006.

9 Briscoe BJ, Özkan N. 1997. Compaction behavior of agglomerated iron powders. Powder Technology, 1997; 90: 195-203.

10 Heckel RW. An analysis of powder compaction phenomena.Transsactions of the Metallurgical Society of AIME, 1961, vol. 221, Outubro, pp. 1001-1008.

11 Mariotto SFF. Fabricação e Caracterização Microestrutural de Sólidos Celulares de Aço Inoxidável 316L Austenítico por meio do Processo de Metalurgia do Pó para aplicações Biomédicas. 2009. 86 f. Tese (Doutor) - Curso de Doutorado em Engenharia Biomédica, Departamento de Instituto de Pesquisa e Desenvolvimento, Universidade do Vale do Paraíba, São José Dos Campos, 2009.

\footnotetext{
* Contribuição técnica ao $69^{\circ}$ Congresso Anual da ABM - Internacional e ao 14ํㅡㄹ ENEMET - Encontro Nacional de Estudantes de Engenharia Metalúrgica, de Materiais e de Minas, 21 a 25 de julho de 2014, São Paulo, SP, Brasil.
} 